\title{
The putative preference for offers over requests
}

\author{
Kobin H. Kendrick \& Paul Drew \\ Max Planck Institute for Psycholinguistics / Loughborough University
}

\begin{abstract}
Requesting and offering are closely related, insofar as they are activities associated with someone's need for assistance. It has been supposed (e.g. Schegloff 2007) that requests and offers are not equivalent actions - specifically that offers are preferred actions and requests are dispreferred. We review the evidence for this claim across a corpus of requests and offers and demonstrate that the empirical evidence does not support the claim for a putative preference for offers over requests. Further consideration of the often symbiotic relationships between requesting and offering, particularly in face-to-face interactions, reveals a more complex picture of the ways in which people recruit others to help, or in which others are mobilized to help.
\end{abstract}

\section{Introduction}

There is anecdotal evidence that among the social niceties we are taught in our early lives are certain norms encouraging or even mandating us, in particular circumstances, to offer things without having to be asked. For instance American children are often taught that they should not bring candy or cookies to school unless they bring enough to offer around to others. Another, though perhaps rather extreme example is that in British boarding schools students used to be, and perhaps still are, instructed that during dinner they were always to take care to offer food, for instance by passing the vegetable dish, to the person sitting to their right, so that no-one need ask - request - anything. As we become adults we learn to offer people assistance when they are in difficulties, to offer them a ride to an event to which both are going, to open a gate when someone whose hands are full is trying to get in (see Enfield, this volume) and other such helpful courtesies. There are no doubt many similar anecdotal accounts of circumstances in which it appears that there is a social value attached to offering, or being offered something rather than having to ask for it; to put it another way, there may be evidence that asking for something - requesting - might be normatively inhibited. As we sit writing this introduction, the two authors have engaged in an exchange in which one rose from the table to get himself a cup of coffee, and as he arrived at the coffee machine, asked the 
other (just in the nick of time) if he too would like a cup of coffee. This being accepted and the cup of coffee duly delivered to the one who remained seated, this other author unscrewed the top of the milk container, poured himself some milk then without putting the top back on the container passed the milk across the table to the one who had poured the coffee. So this exchange consisted of two offers, one verbal and the other made through a physical action; had each not offered the other, each would have had to have asked for the substances they so urgently needed to continue this task of composition! Many of the minor and unnoticed interactions in daily life seem to be organised in just such a way; we offer what we anticipate others might need, without waiting to be asked. All of which might be related, in various ways, to the social solidarity principle in social life, a principle promoting co-operation and social cohesion, and likewise inhibiting whatever might compromise or threaten that cohesion (Goffman 1955; Heritage 1984, 265-269; Clayman 2002).

It is perhaps this [+] value associated with offering and [-] value attached to having to ask - and note the connotations of the expression "having to ask" - that lie behind claims that offers are "preferred" in interaction and that requests are dispreferred actions. Intimations of a putative preference for offering rather than requesting, according to which requests are dispreferred, are to be found variously in Schegloff (1979, 49), Levinson (1983, 343), Lerner (1996), Lindström (2005), and Robinson and Bolden (2010), all of which can be traced back to Sacks (1992b: 207), who claimed that " $\mathrm{t}]$ here is in general a difference between requests and offers, a preference for offers over requests". However, the clearest statement supporting this claim is made by Schegloff $(2007,83-84)$, who argues that the evidence that offers are preferred over requests is fourfold. First, requests tend to occur later in interactions than offers; second, requests are accompanied by accounts, mitigations, excuses and other features associated with dispreferred responses (Heritage 1984, 269-273); third, requests often appear to be withheld until they can be done as reciprocal actions (Sacks 1992b, 409); and fourth, requests can masquerade or be disguised as other actions. ${ }^{1}$ Lerner (1996) takes a similar view about the preference for offers over requests, adding a fifth piece of evidence, that offers can be made in such a way as to pre-empt a speaker who it appears might be leading up to making a request - anticipating what the other might need, the offer is made at just the point at which the request is recognisable.

1. On the withholding of a request, Sacks says the following: "having some request to make of another you can, when you get into a conversation, hold off making that request under the possibility that the other will ask you for something or you will end up doing something for them, at which point your request stands as something they can do for you in exchange for the thing that they just acknowledge that you just did for them" (1992b, 409). Note that Sacks formulates this as a possibility ("you can..."), not a general propensity. 
Plausible though this putative preference for offers over requests might seem, and however well it accords with the kind of norms and patterns outlined above, the evidence supporting these claims has not been systematically explored or tested against large data sets. We will argue here that when we review the evidence held to support this claimed preference, this evidence is equivocal at best, and significantly misrepresents some of the most salient dimensions of offering and requesting in ordinary social life. In this paper we will review and assess the evidence that Schegloff proposes as supporting this putative preference. We will then consider some of the more general dimensions and factors associated with the relationship between offering and requesting, demonstrating that there is no straightforward or unitary preference privileging offers in circumstances where a request could be made. Indeed we find ourselves converging on a point that Sacks made in a lecture in 1970, that "[o]ne wants then to reconsider these objects - offer, request, warning, threat - not as though they're a series of different things, but to see them as sequential versions of something" (Sacks 1992a, 331).

\section{When do requests and offers occur in conversation?}

As evidence in support of the status of requests as dispreferred actions, Schegloff makes a general claim about the temporal position of requests in conversation, observing that "[r]equests appear disproportionately to occur late in conversations" (Schegloff 2007, 83). The statistical nature of this claim allows it to be easily tested. We have reviewed 58 offers and 39 requests in telephone conversations. An analysis of the temporal position of these actions does not support Schegloff's claim. Requests are distributed in a bimodal fashion with the greatest frequency of occurrence near the beginning of the telephone call, and a lesser frequency towards its end.

This likely reflects a bias towards the occurrence of requests in a "reason for the call" position (Schegloff \& Sacks 1973). In contrast, offers tend to occur later or towards the end of calls, with a much lower frequency in the "reason for the call" position. In short, the inverse of Schegloff's (2007) claim seems to hold in our data: requests disproportionately occur early in the call, as reasons for the call, whereas offers occur much later, as shown in Figure 1.

The graph below shows the distribution of offers $(n=58)$ and requests $(n=39)$ in a sample of English and US telephone data. The $x$ axis represents the temporal position of the actions as a proportion of the duration of the call $(0=$ start of call; $1=$ end of call). The $y$ axis represents the frequency of occurrence of the action. The peaks of the density curves represent the most frequent positions of occurrence. The graph shows that requests most frequently occur near the beginning of the call, whereas offers most frequently occur towards the end. 


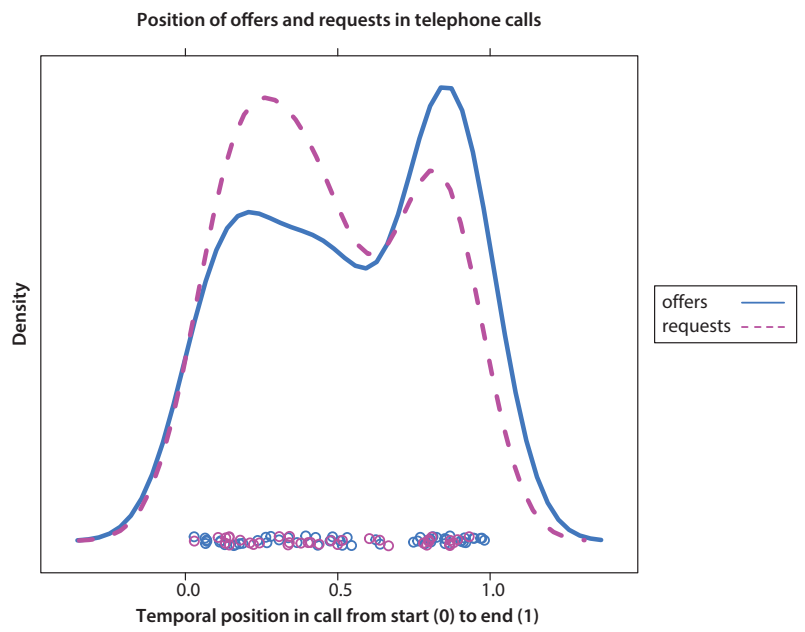

Figure 1. Temporal distribution of requests and offers in telephone conversations

This pattern of distribution seems contrary to Schegloff's claim that:

Requests appear disproportionately to occur late in conversations, as late topics or even as ostensible afterthoughts, i.e. done after the initiation of the conversation's closing, and seem especially problematic and unlikely to occur in first topic position. For example, some phone calls which appear (in retrospect upon their completion) to have been made specifically to do a request may have several topics raised, and other sequences worked through, before the request is articulated.

(Schegloff 2007, 83)

Whilst Schegloff does not cite examples of such "delayed" requests, delayed even until after the closing has been initiated, such delays do certainly occur. However, the distributional claim that requests "appear disproportionately to occur late in conversations" is not supported by the statistical evidence. Cases in which requests are made in first topic position in calls occur quite frequently and unproblematically, as in these examples.

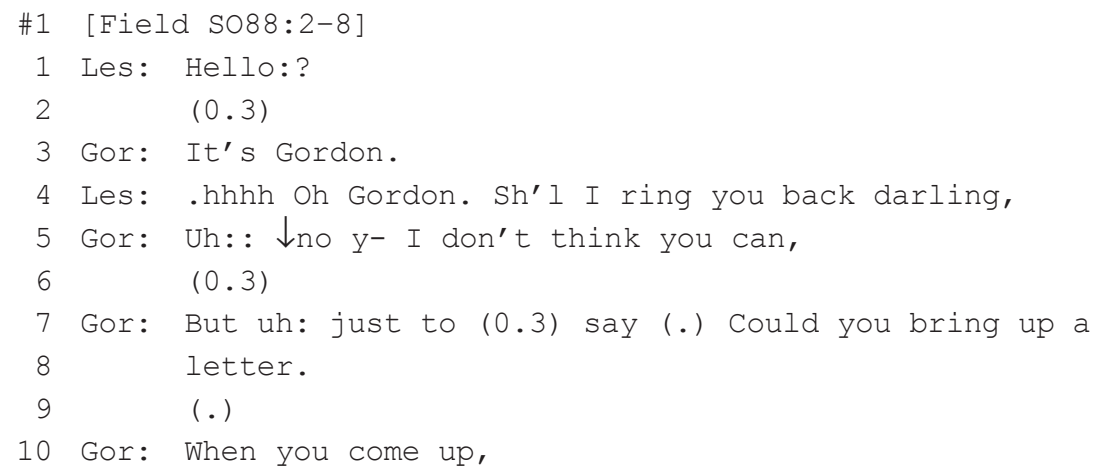




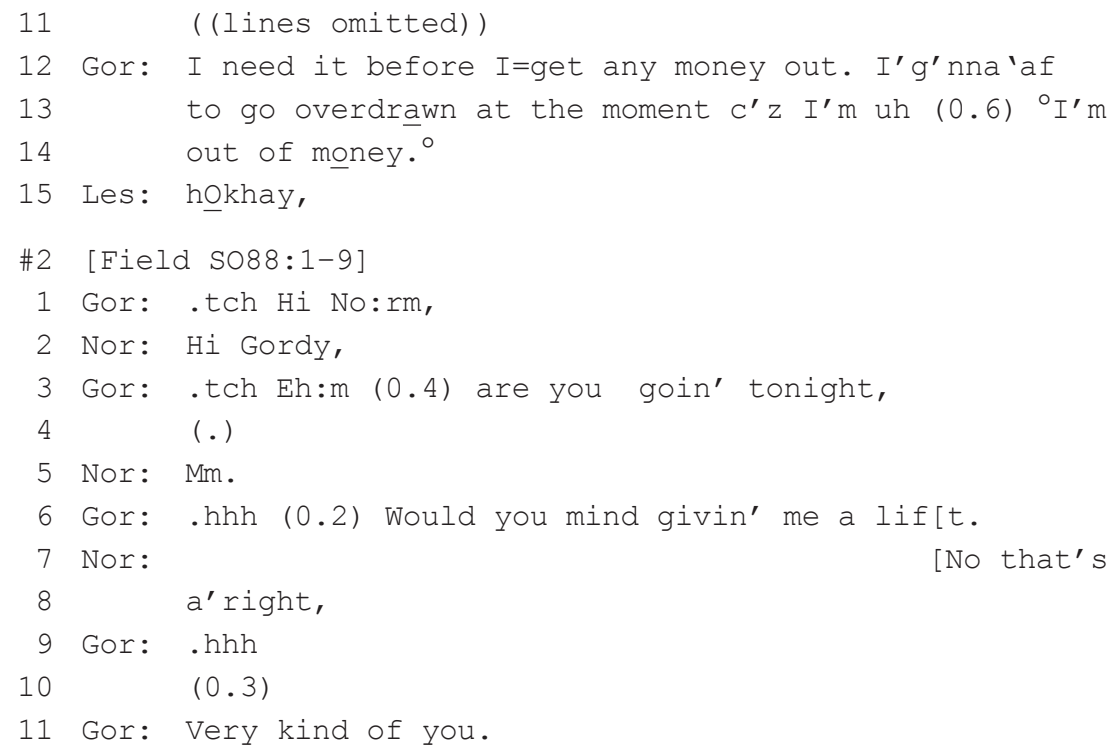

In each of these examples, there is no evidence that the request is delayed by other prior topics in such a way as to defer them, and certainly not until near the end of the call. Moreover, it is worth observing that in Extract 1 the "object" of Gordon's request (that he wants his mother to bring him a certain letter) is not something that she might have anticipated and hence offered before being asked. This matter of whether the recipient of a request might have been in a position to anticipate what is requested, in a sense to have anticipated the need, is perhaps a variable dimension of such sequences. For instance, when in Extract 2 Gordon asked Norm if he was going tonight, Norm plainly knows what's being referred to; and since this is evidently something to which Gordon is also going, and perhaps knowing or guessing that Gordon might need transport to the event, Norm might have stepped in and offered him a lift (a ride). We have examples of just such sequences, in which an enquiry that looks as though it might be leading to making a request elicits a response in which the recipient offers something. But the recipient would need to be pretty sure why the other is asking; here for instance Norm would need to be sure that Gordon is asking because he wants a lift, and not simply in order to check which of his friends is going to the event, whether they might have a drink before or after, or any of the many other matters that might be associated with an evening's event. In certain respects the claimed preference for offering assumes that requesting and offering are equally "available" and alternative actions, on a given occasion; which is to say that a participant may anticipate what the other "needs" and hence offer before being asked. But this is not uniformly the case; anticipation of need is contingent on the details of the interaction, what one knows about the other and so forth. But for the present our point is that Schegloff's distributional claim is not supported by the data. 


\section{The turn design of requests and offers}

Schegloff suggests that requests are "regularly accompanied by accounts, mitigations, candidate 'excuses' for the recipient, etc. which are done in advance of the request itself" (Schegloff 2007, 83). Here is the example Schegloff shows.

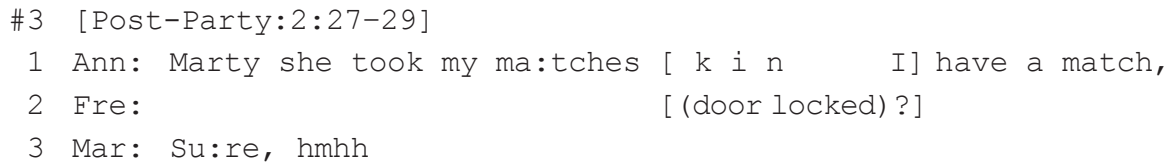

Here in line 1, before asking for a match, Ann explains that Marty she took my ma:tches. Schegloff observes that whilst by no means all requests are accompanied by such accounts, "the recurrent provision of accounts with requests is one of a constellation of features pointing to its relatively dispreferred status" (Schegloff 2007, 83). This evidence of the characteristically dispreferred status of requests would seem to suggest a contrast with offers; if these are the preferred alternatives to requests, Schegloff's reasoning implies that offers would not be accompanied by accounts. In fact, one finds that requests can perfectly easily be made without prefatory accounts, as the two examples of requests in first topic position above indicate. Furthermore, very many offers are accompanied by accounts, which is to say they are preceded by or led up to through some form of explanation or account of the circumstances of making the offer. Consider Gladys's offer to lend Emma her newspaper in Extract 4.

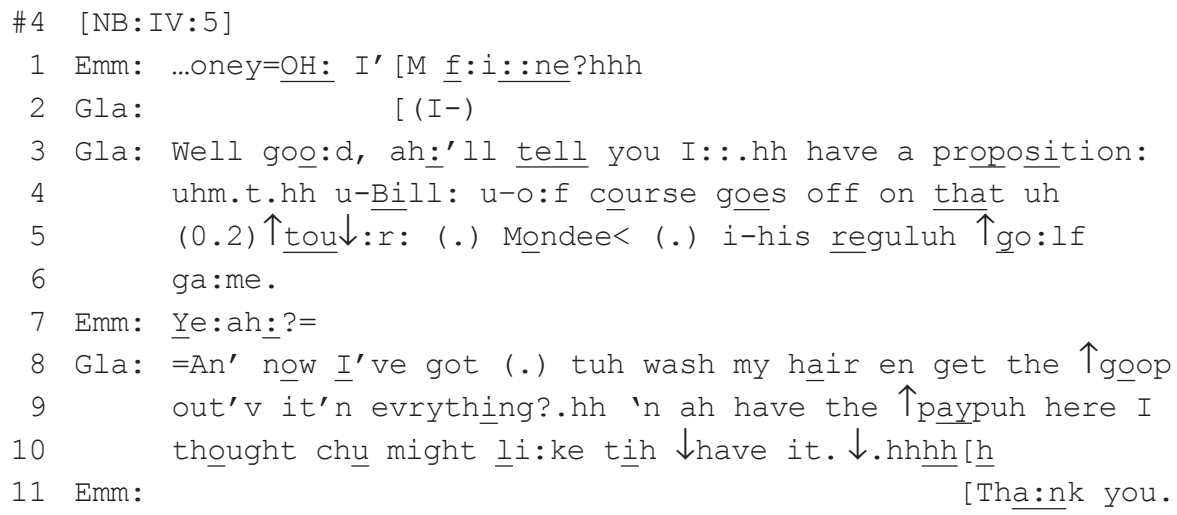

In lines 4-9 Gladys gives an account of why she doesn't need her newspaper (ending with I've got to wash my hair) and hence how it is available for Emma to borrow. Here are two further examples of offers preceded by accounts - a quite brief account in the case of Edgerton's offer in Extract 5 (lines 7-9), but more extensive in Leslie's account for offering Mary's husband the address of a contact, in Extract 6 (lines 5-31).

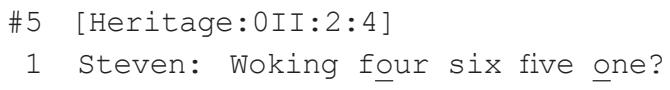




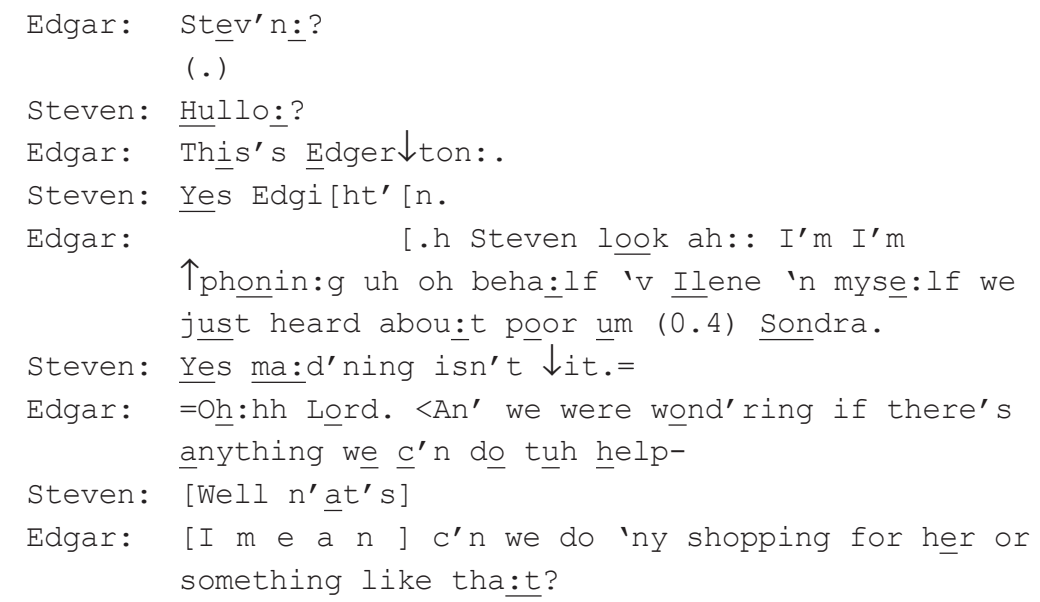




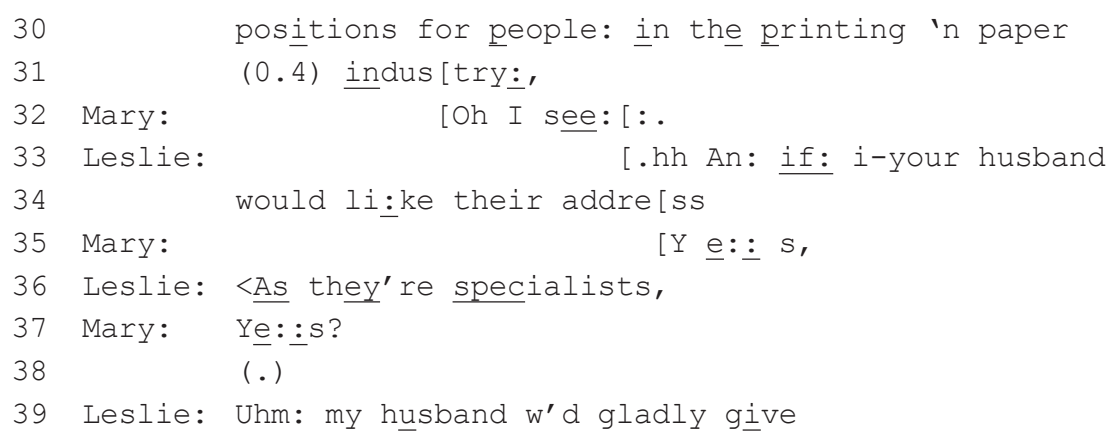

Leslie's offer is not made until lines 33-39, before which she gives an extensive account for making the offer, marked from the beginning as a slightly delicate matter (I hope you don't mind me getting in touch, then your husband ... told us something of what had happened - which is that Mary's husband has lost his job; note also lines 13-17 in terms of a certain awkwardness in making this offer). Leslie's account covers not only the difficulties that her offer addresses, but also the circumstances that make it possible to offer assistance (at least by giving Mary's husband a contact).

We have noted that Leslie begins her account in such a way as to indicate that this might be an awkward or delicate matter. Note also that in addition to the accounts accompanying (preceding) each of the offers in Extracts 4 and 5, the offerer prefaces his/her turn with components (I'll tell you and Look I'm phoning on behalf of Ilene and myself, respectively) effectively delaying not only the offer but also the account; in each case the offers seem to be designed to display an orientation to the delicacy of the matter of offering. Thus we may suggest that the delay in the actual production of the offer is not a reflection of the status of the action as dispreferred - as has been suggested for requests. Rather the prefatory work in these examples orients to and serves to manage the delicacy or awkwardness of these particular offers (of what's being offered). To put this differently, just as requests may engender impositions and obligations on the other person, so too may offers engender obligations on the other and may put the other in one's debt for even small services (such as loaning them one's newspaper), and imply something about their need for such assistance or services. The (negative) connotations that might be found in or attributed to an offer can be every bit as awkward or "face threatening" as the risks of imposing on another by requesting their assistance (Brown \& Levinson 1987). The accounts that accompany offers may orient precisely to such matters of obligation and debt.

That having been said, many offers are not accompanied by accounts. Each of the offers in Extracts 4-6 are in first topic position in these telephone calls; indeed the reason for the call is to make an offer - and all such "reason for the call" offers are prefaced with similar kinds of accounts or explanations for making the offer. However, offers may be made in direct response to the recipient's immediately prior description 
of a trouble or a problem (Drew 1984; Curl 2006). Such interactionally generated offers typically do not include accounts.

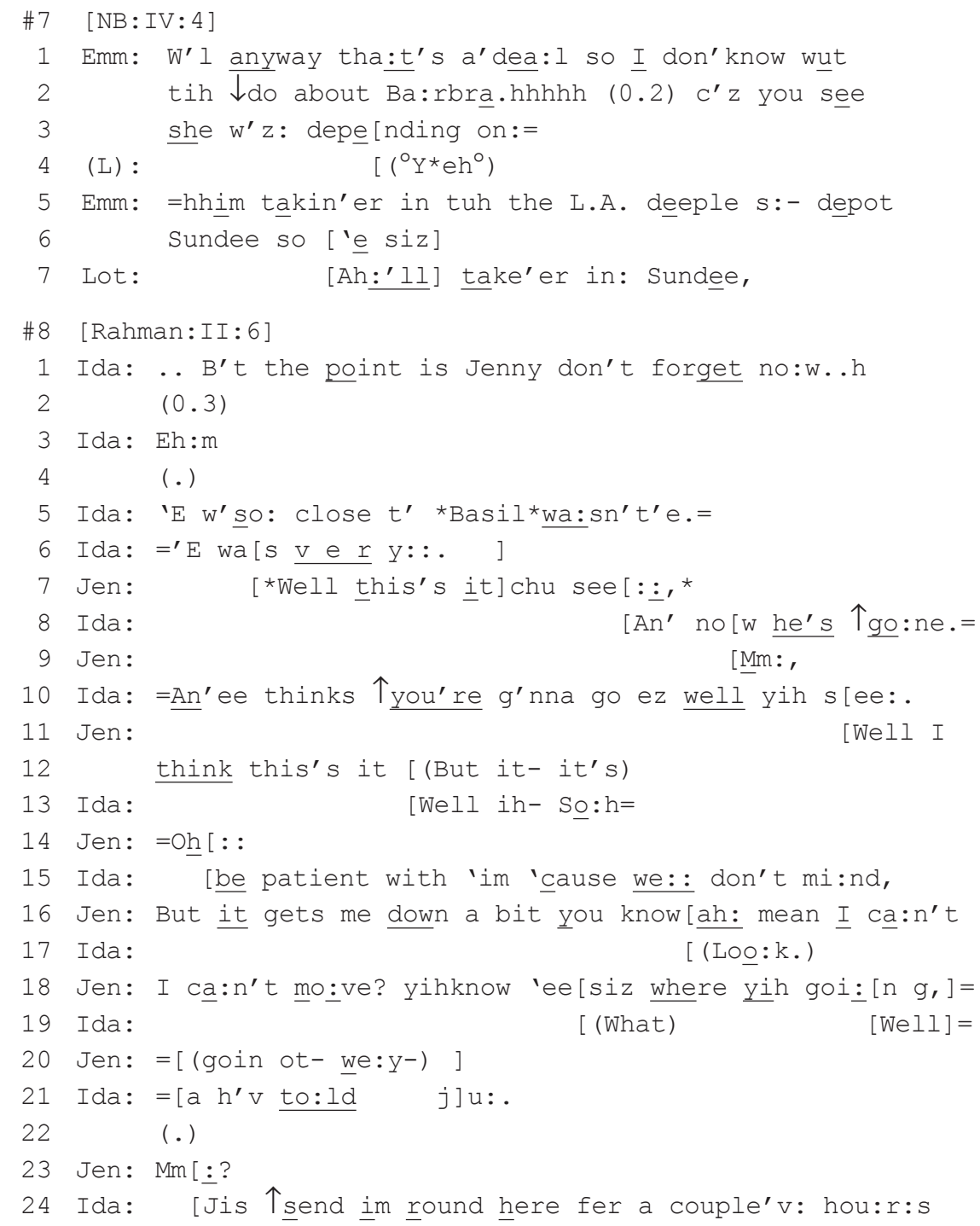

In Extract 7 Lottie offers to assist by taking Emma's daughter to the bus depot at the end of the Thanksgiving holiday (line 7); and in Extract 8 Ida offers to help Jenny by minding her young son for her (lines 21-24). In each case, these offers are occasioned by the other's description of a problem, respectively Barbara's need for a ride to the bus depot (I don't know what to do about Barbara), and the problems Jenny is experiencing with her young son who is afraid of being left alone since the death of her husband Basil (and now he's gone, line 8). These descriptions in the immediately prior turns 
serve to provide an account for the subsequent offers. An account by the offerer is therefore unnecessary in this position - the offer relies on contiguity by trading off the prior problem description/account.

So with respect to Schegloff's argument that part of the evidence for the dispreferred status of requests is that they are recurrently accompanied by accounts, it is apparent that the very same turn-constructional features are evident in offers. Hence there is perhaps an equivalence between requests and offers, insofar as they both exhibit similar turn design features.

\section{One action masquerading as another}

Schegloff observes that "[o]ne evidence of the treatment of requests as dispreferred is the masking of them as other actions - often as ostensible offers" (Schegloff 2007, 84). Once again, this would seem to imply a contrast in which requests may be disguised to appear to be other actions, whereas offering does not need to be disguised as anything else - what you see is what you get! Schegloff provides a single case in which, he argues, a request is done in such a way as to masquerade as an offer. However that may be, it is true that offers may also be done - designed and managed - in ways that are less than explicit or on-the-record, and may even be disguised as other actions.

For instance, it is notable that in each of the following cases the speaker is offering something to the recipient, and that the recipient responds in such a way as to make it clear that they understand they are being made an offer. However, in each case the offer is not made in a canonical or explicit form (on which see Curl 2006); rather, the speaker informs the other (I have plenty of canned goods, and Where my husband works they're actually going to advertise one in the near future) or issues a directive (Just send him round here for a couple of hours).

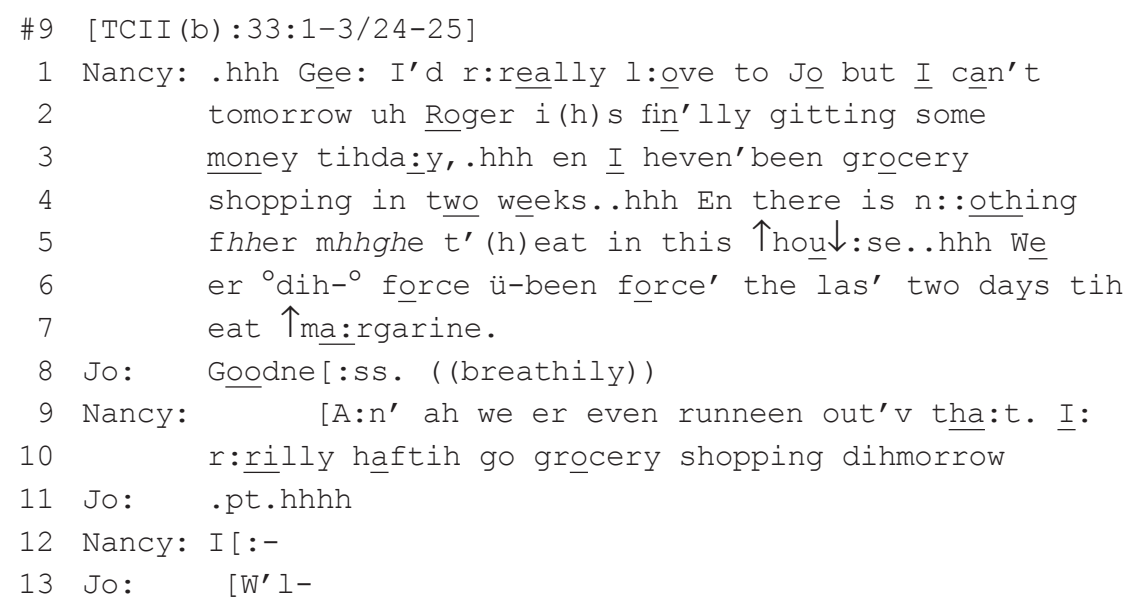




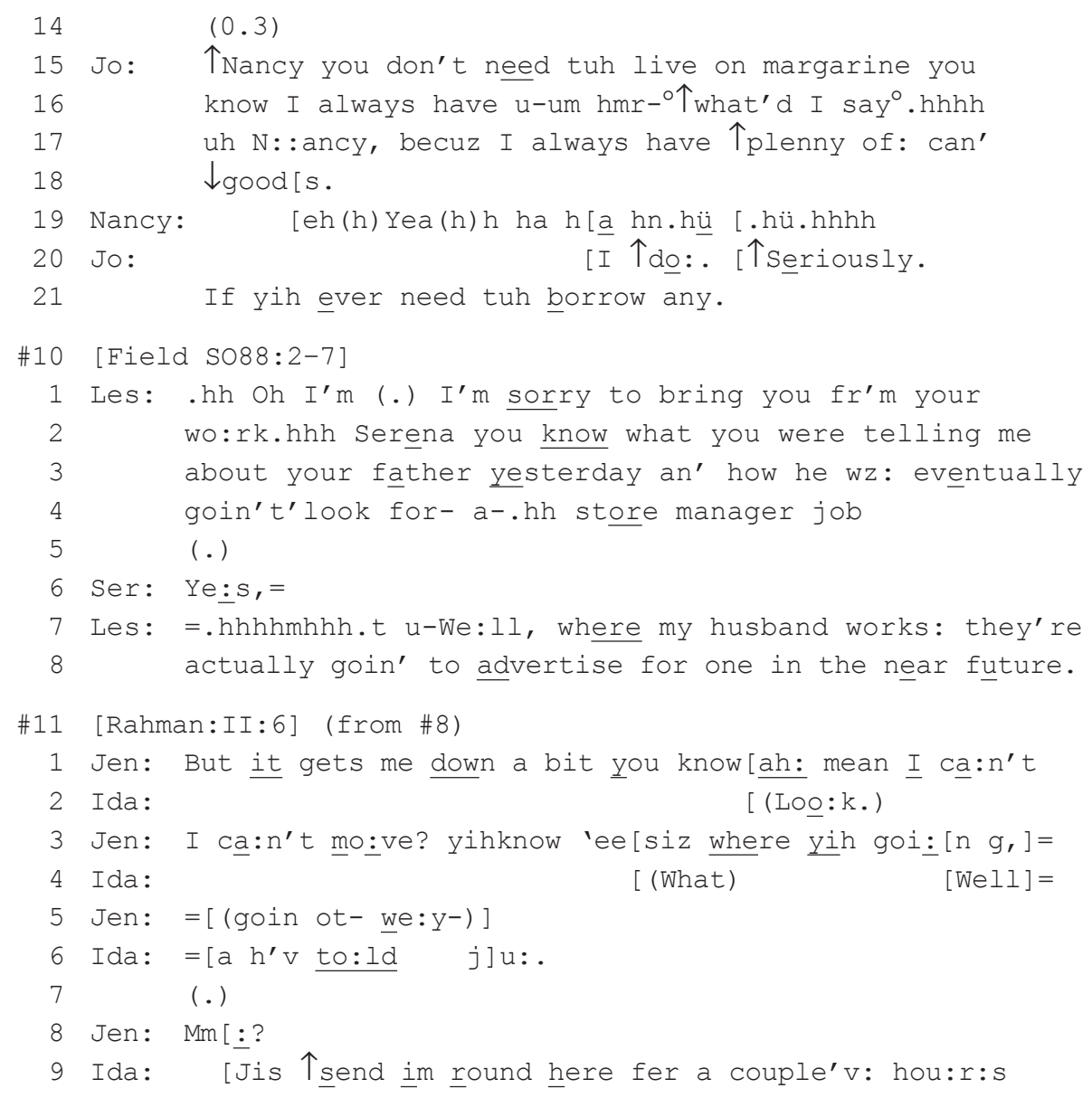

In just the same way that a shopkeeper may request a customer to put some produce on the scales to be weighed by saying Wanna put that on the scale?, that is, through a turn construction that is not explicitly a request format, so too the speakers in these examples are offering something without using explicit offer formats (again, Curl 2006). If there was a simple binary in which requests are dispreferred actions and offers are preferred, offers would not be done through the kinds of indirect forms illustrated above, but instead would be conducted only through explicit, unequivocal forms - as is the case for preferred responses which are delivered through "simple and unvarnished" forms (Heritage 1984, 266).

In other cases, speakers do not merely construct their offers through indirect forms; they go further, in "disguising" their offers in other ways, for instance by explicitly formulating their action as something other than an offer. In Extract 4, repeated below, Gladys refers to what she is about to make as a proposition. 


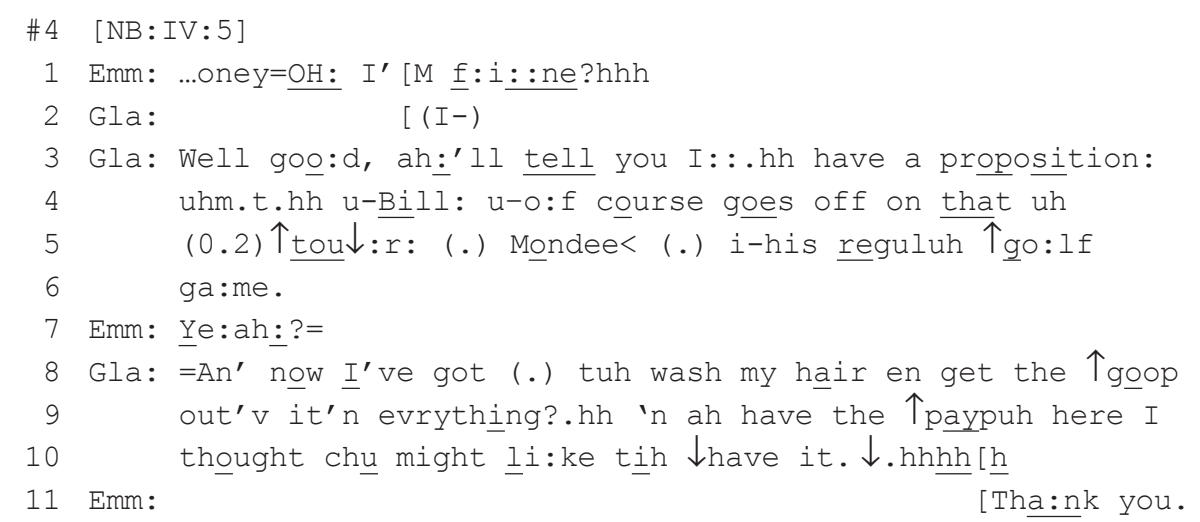

Gladys is, as we noted earlier, offering Emma the use of her newspaper, explaining why for the time being she doesn't need it. Emma's response in the last line of the excerpt indicates clearly that she understands Gladys as having made an offer, one that she promptly accepts. But Gladys did not use one of the canonical forms for offering, instead formulating what she's about to do as a proposition, and then using a construction which seems closer to making a suggestion (I have the paper here and I thought you might like to have it).

We should make it clear that our point here is not to deny that requests may be done in indirect or even disguised forms - they clearly can be. However, offers may equally be constructed through indirect forms or in ways that lay claim to be something other than offering. The relationship between the form that an action takes (its mask, as it were) and the action itself is often not straightforward (Schegloff 1984). This is true not only for requests that may be packaged as other actions, but also for offers, as the examples above illustrate. The cases of offers that we have examined above argue for an equality between offers and requests rather than the complementarity that has previously been suggested. To argue for a preference of offers over requests would require not only demonstrating that requests are dispreferred actions, but also showing that offers are their preferred alternatives; this has not been done - indeed the thrust of what we have shown above is that offers can be just as awkward to make as it can be to (have to) ask for something, in certain circumstances.

\section{Do offers forestall requests?}

In a paper that is not otherwise focused specifically on requesting and offering, but is rather concerned with anticipatory completions - a location which involves "a preference organisation for alternative actions" - Lerner (1996) argues that as a speaker is articulating a preliminary component (about a problem of some kind) to what will 
become a request, a recipient may anticipate where the speaker is heading and intercept by making an offer, thereby saving the speaker the trouble of having to make a request. Drawing on Sacks's suggestion that "[i]n the case of pre-requests, one thing a pre-request regularly elicits is an offer. If you get an offer you need not make a request" (Sacks 1992a, 685), Lerner shows examples in which recipients seem to anticipate what the speakers want and intercept with an offer. These are the two cases he shows as evidence (Lerner 1996, 315).

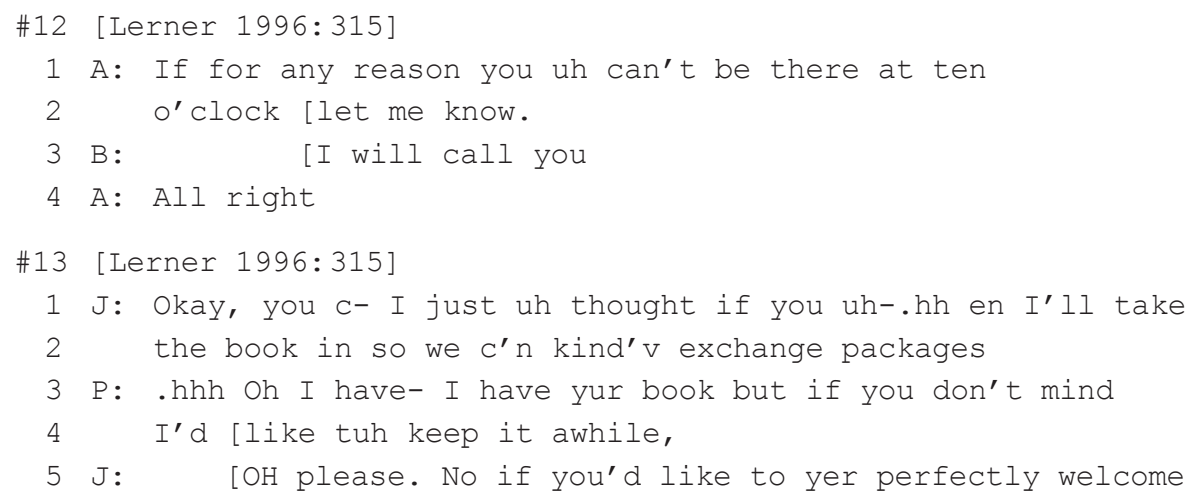

The evidence proposed in support of the preferred status of offers, and the dispreferred status of requesting, is that in these cases the recipients, B and J respectively, intervene before the speakers have completed their turns; and that they intervene to offer that for which the speakers were seemingly going to ask. We should note that these cases involve social norms and obligations of conduct that do not generalise to all offers and requests. In the first case, speaker B has apparently already agreed to meet the other at a specific time, an agreement that carries with it certain obligations if it cannot be upheld. In the second case, the request to keep a borrowed book and the offer to lend it involve pre-established norms of reciprocity. We can contrast this with other perhaps more frequent requests, such as Gordon's request in Extract 2 to his mother to bring up a letter when she visits, in which no such social norm or preestablished agreement enable the other to anticipate the request with an offer. The complementarity of offers and requests that Lerner's data seem to suggest may have more to do with the specific activities in question than with a general preference for offers over requests.

However, an additional feature of these examples is that in both cases the speakers A in Extract 12 and P in Extract 13 - continue their turns to completion, and in doing so fully complete their requests, simultaneously as the recipients make their offers (see their continuations after the overlap onsets in lines 2 and 4 respectively). But if offers were preferred actions, then we would expect $\mathrm{A}$ and $\mathrm{P}$ to abort their turns, as soon as it becomes clear that their recipients are intervening "on their behalf" by offering what 
they had been going to ask. A similar case in our data is the following, though here a speaker who is plainly in the course of making an offer is intercepted by the other making a request.

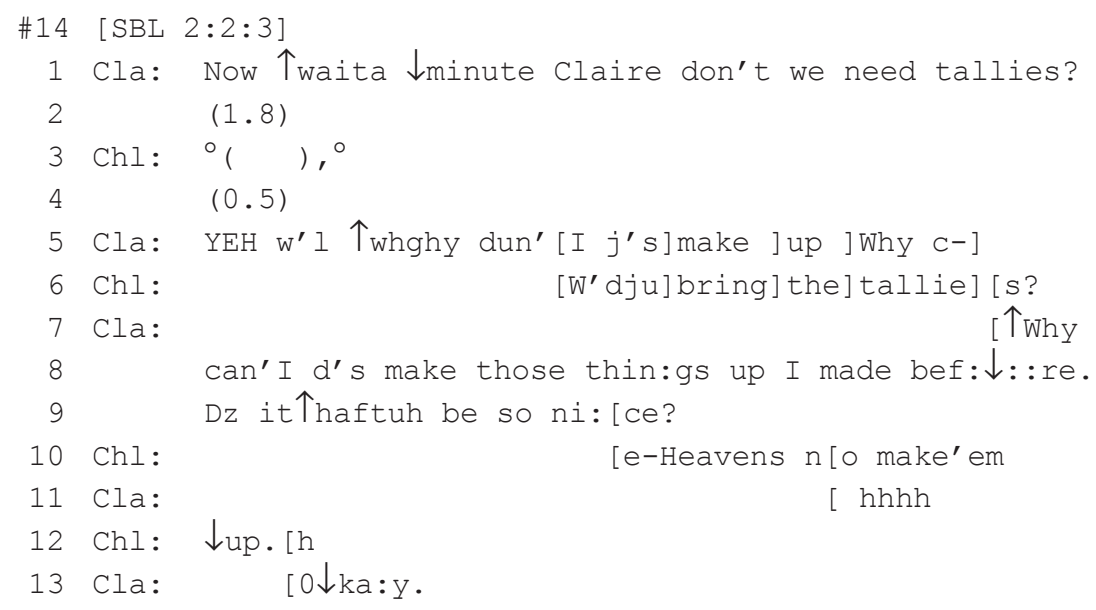

Claire and Chloe play bridge (the card game) with a bunch of their friends, taking it in turns to host each occasion. Chloe is hosting their next game; at the point this extract begins (line 1), she realises that she doesn't have tallies (score sheets). In response to this, Claire begins to offer to make up some tallies (line 5) - the pattern here being very much the same as the one we have shown in Extracts 7 and 8; when one speaker talks explicitly about a problem or trouble they have, the other responds by offering to assist. So Claire is offering a solution to Chloe's problem (why don't I...). But this does not in any way inhibit Chloe from interjecting to ask Claire to do precisely what Claire was offering to do (see the overlap between them in lines 5 and 6). Whilst Claire persisted in making her offer over Chloe's request (and note that Chloe right away accepts Claire's offer in lines 10 and 12, make them up), nevertheless Chloe had no need to make the request in the first place (line 6); hearing that Claire was offering, if a request were really a dispreferred action, then she could easily have desisted. These examples seem to demonstrate that something can perfectly well equally be offered or requested; the data do not demonstrate any putative preference for one over the other.

\section{What is the relationship between offers and requests?}

Thus far our approach has been to review the evidence proposed in the literature, primarily by Schegloff (2007), in support of the preference for offers over requests; we have shown that the evidence does not support that conclusion. We do not mean 
to suggest, however, that there is no relationship between offering and requesting in conversation (and for further consideration of some relationships between requesting and offering, see Clayman \& Heritage, this volume). Indeed, as we have already seen, our data reveal a number of recurrent and relatively concrete relationships between offering and requesting. These relationships, and the symbiosis between offers and requests that they point to, derive in large measure from specific circumstances of need, commonly but not invariably embodied in requests; these relationships derive also from the possibility that one way of being solicitous is to anticipate the needs of others, by offering assistance. This symbiotic relationship is one aspect of social solidarity and social cohesion, but it is a contingent relationship, built upon particular circumstances, not a general preference for offers over requests. In this section we describe, quite schematically, five recurrent and relatively concrete relationships between offers and requests, which might be considered in lieu of a putative preference for offers over requests.

\subsection{Requests can occur in response to offers}

A first relationship between offers and requests involves the occurrence of a request in next position after an offer, either as a response to the offer or as a counter to it. The sequence in Extract 15 come from an interaction between two university students outside a campus bar. As one gets up to get another beer, he offers one to his friend as well. The design of the offer begins with a format that would have named a specific object (e.g. "do you want a beer?" or "do you want a Bulmers?"), but this is self-repaired to a format that leaves the object of the offer open.

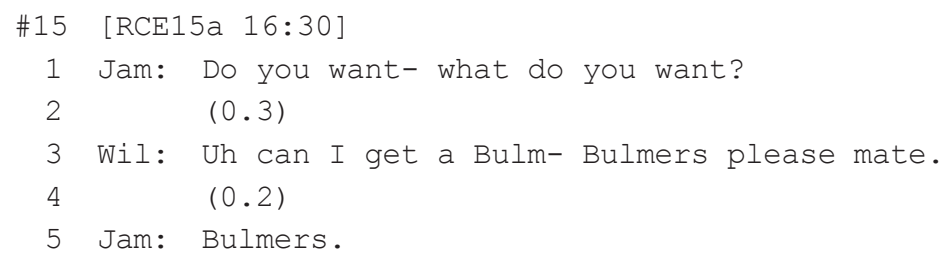

In response to the offer, the recipient employs a request format ("can I get an X?") that accepts the offer and specifies the object. The function of a request format in response to an offer, as an alternative to simply naming an object, is to treat the exchange as contingent upon the first speaker's acceptance, even though an offer has just been made.

A request can also occur in next position to an offer as a counter to the initial offer (on counters see Schegloff 2007, 16-18). The sequence in Extract 16 comes from an interaction between a mother and her young son as she prepares him for bed. After the mother offers to read a book to her son, the son counters with a request to play a game instead. 


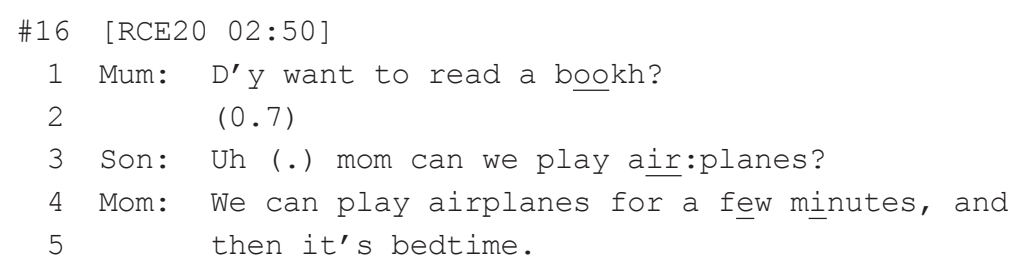

The mother's initial offer of an activity provides a warrant for the son to make a request for an alternative activity (see Goodwin \& Cekaite, this volume).

\subsection{Offers can occasion requests}

A second relationship between offers and requests holds only in multiparty interaction and presumably only for a specific class of shareable objects. Under such circumstances, an offer of an object to one participant can serve as an occasion for requests by others. In Extract 17, drawn from a group interaction between five university students on a campus lawn, the offer of a biscuit to one participant occasions requests by three others. The sequence begins as Sarah notices Jessica eating a biscuit, which she had discretely retrieved from her bag moments earlier.

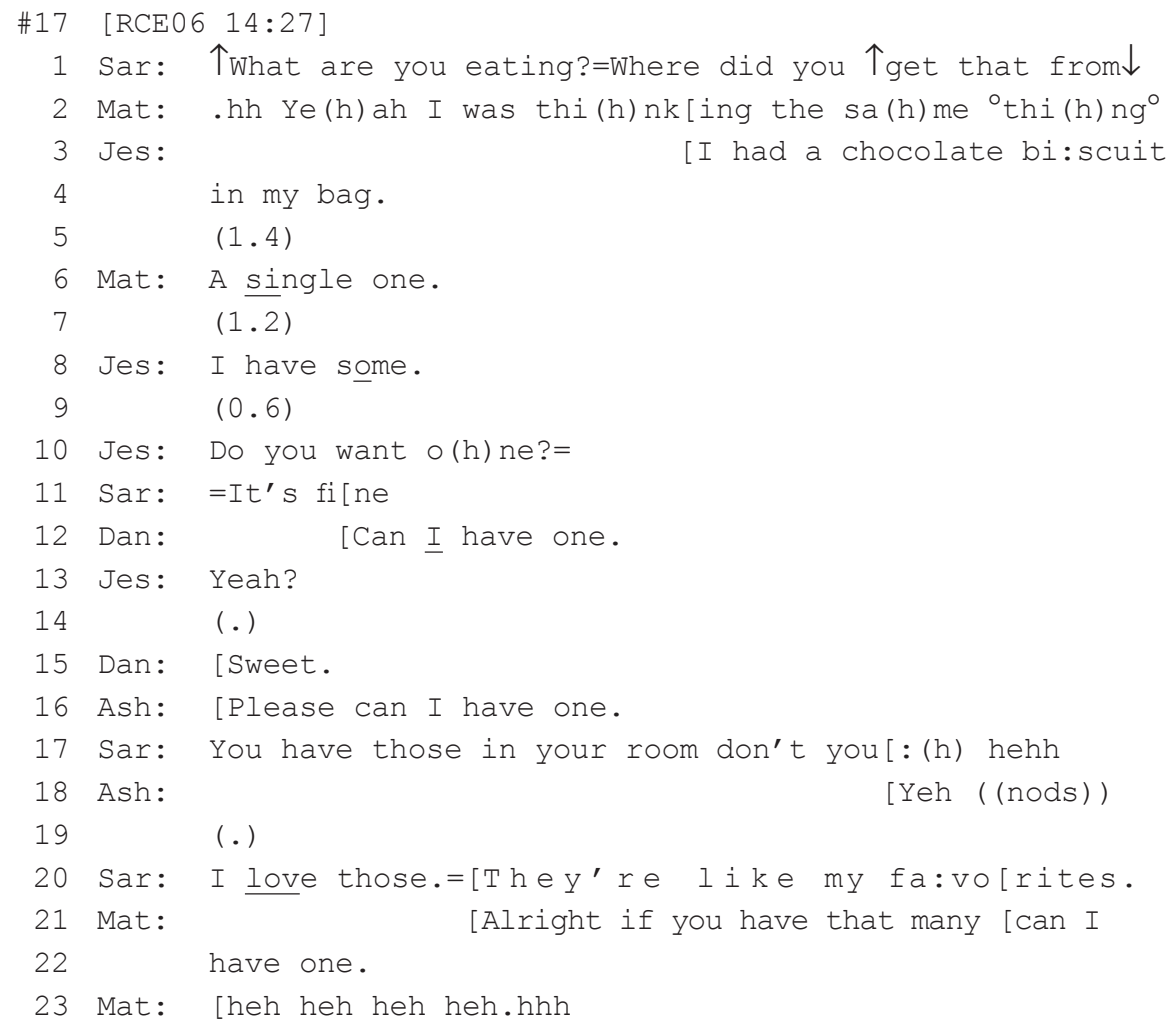


24 Dan: [heh heh heh heh

25 Ash: Thank you.

26 Jes: They're a bit melted.

Although there is evidence that both parties, the offerer and the requesters, initially withhold their respective actions, once an offer is made to Sarah (at line 10), requests by Daniel, Ashley, and Matthew quickly follow (at lines 12, 16, and 21-22). The first request comes after Sarah refuses the offer (line 11) and is designed, with stress on the first person pronoun $I$, to build a contrast between the current request and the previous refusal. Both the initial offer and the granting of the first request provide local warrants for other participants to follow suit with requests of their own. The cascade of requests that occurs in this sequence is also presumably contingent upon the nature of the object. The properties and affordances that constitute the object in question as shareable may include the status of the object as edible, the availability of the object (e.g. whether there is a single biscuit or multiple), and the object's divisibility, which affords relatively easy apportionment.

\subsection{Requests can occasion offers}

A third relationship between offers and request is the inverse of the second: a request to one participant can serve as an occasion for an offer by another. Requests publically display, and seek a solution for, the needs, desires, problems, etc. of speakers; and a request for an object or service that satisfies one need may occasion an offer that satisfies a similar or related need. In the sequence in Extract 18, which is drawn from the early moments of a family mealtime as the members of the family prepare the table, a series of requests to one member of the family occasions an offer by another.

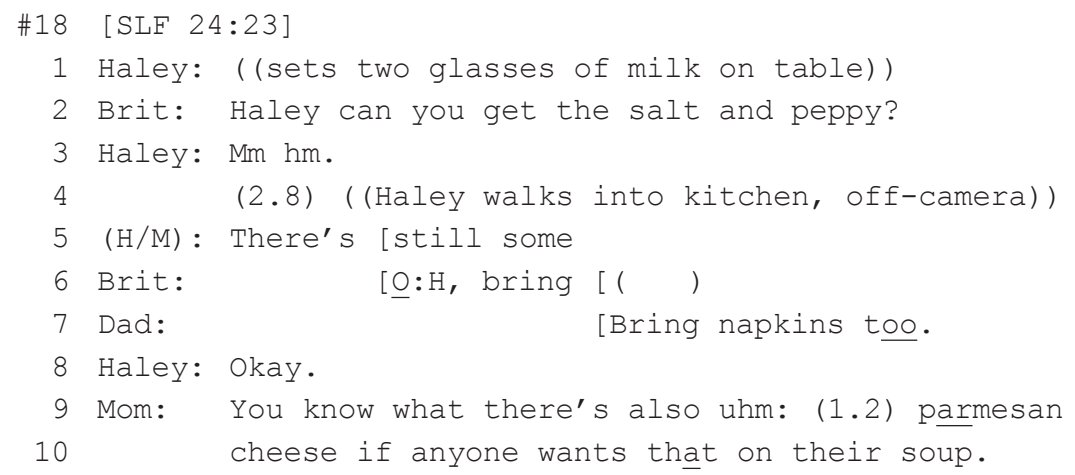

After Haley sets two glasses of milk on the table, one at her father's place at the table and one at her own, her sister, who is already seated, asks her to bring salt and pepper to the table (line 2). Similar to the previous case, in which an offer to one provided a warrant for requests by others, here Haley's actions, having just delivered items to the 
table, and her current position, having not yet sat down, create an opportunity for her sister's request. Likewise, Haley's granting of this request (at line 3) and her move to the kitchen to fulfil it provide an opportunity for her father to ask Haley to bring napkins to the table as well (line 7). It is in this sequential environment, after multiple requests that contribute to the activity of setting the table, that an offer is made by the mother, who is also in the kitchen, an offer which similarly concerns provisions for the meal (lines 9-10). The mother's offer anticipates a possible need or want, for an item that she treats as unknown to the recipients, using a declarative format and a you know what-preface, and hence is not requestable.

Here is another example in which Leslie's "request" for a ride (lines 13-14) is responded to with Carrie's offer to collect her (line 15). (Leslie's request for a ride somewhat masquerades here as some kind of request for permission, though it's transparent that Leslie is asking Carrie to take her on to the event to which they're both going that evening.) They struggle for a few lines between Leslie's request for a ride from Carrie's home, and Carrie's offer to call by Leslie's home to collect her; but in the end Leslie gives way (line 27).

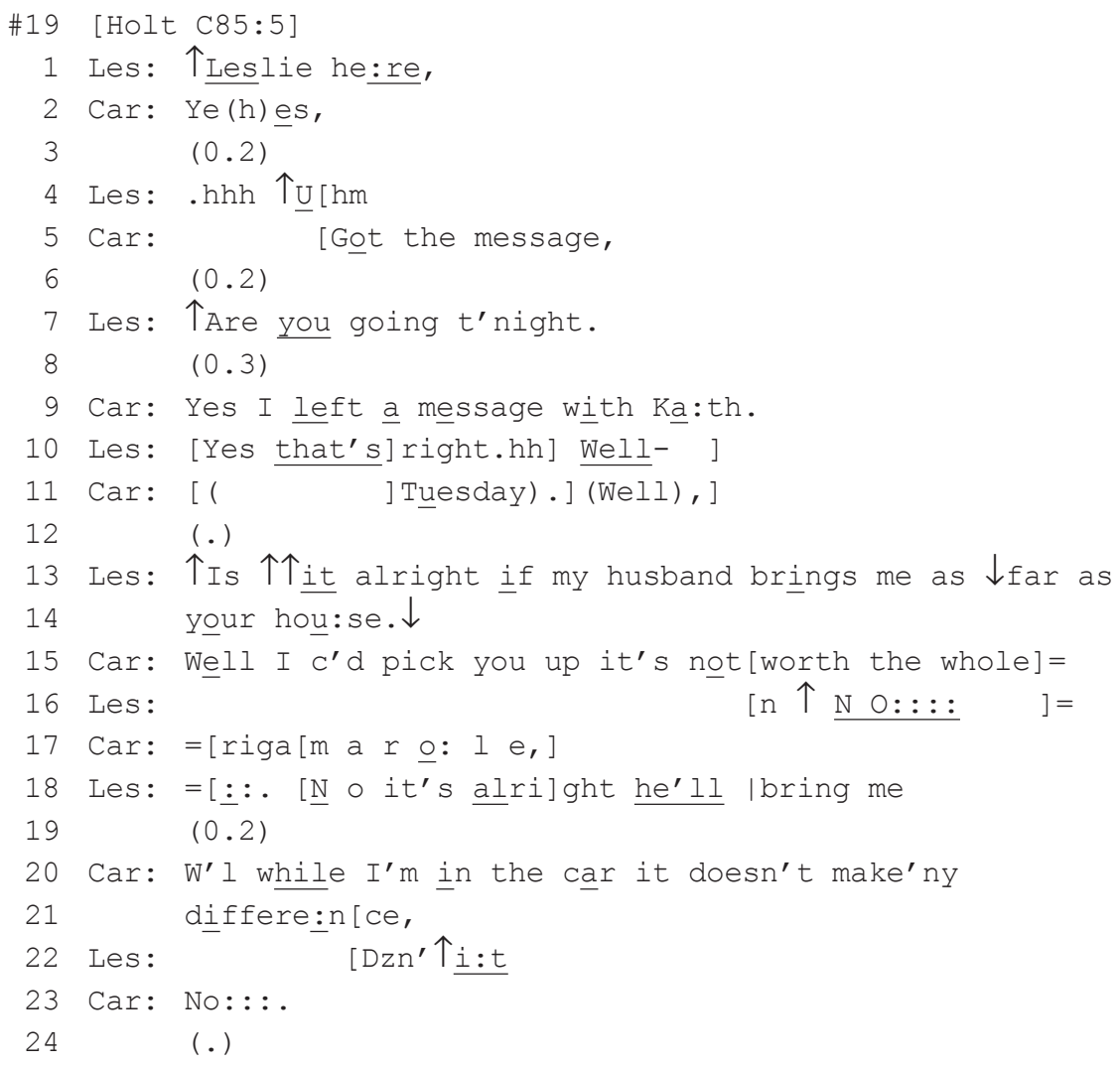




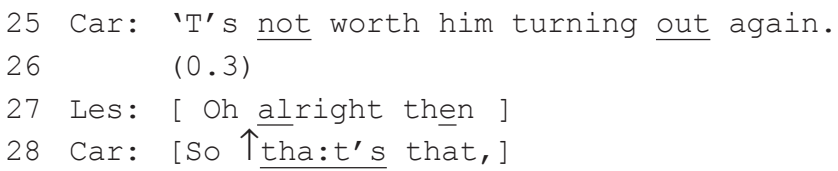

These cases demonstrate that requests and offers can constitute complementary contributions to an activity or course of action and, furthermore, that within the context of an on-going activity, requests can occasion offers, just as offers can occasion requests.

\subsection{Reports and displays of problems can elicit offers of solutions}

A fourth relationship between offers and requests is associated with a pattern that we have seen earlier, in Extracts 7, 8 and 14, and concerns not requests per se, but a practice that might be regarded as an alternative to requesting: namely reporting and displaying a problem, trouble, lack, or need. A report or display of a problem is an alternative to a request insofar as problems establish the relevance of solutions, and requests ask for solutions to problems whereas reports or displays do not. As Drew (1984) and Curl (2006) have observed, reports of problems routinely occasion offers of assistance. So as we saw for instance in Extract 7, repeated as Extract 20 below, Emma's report of a problem, namely that she needs to get her daughter to the bus depot, establishes the relevance of an offer for help, which Lottie makes in next position.

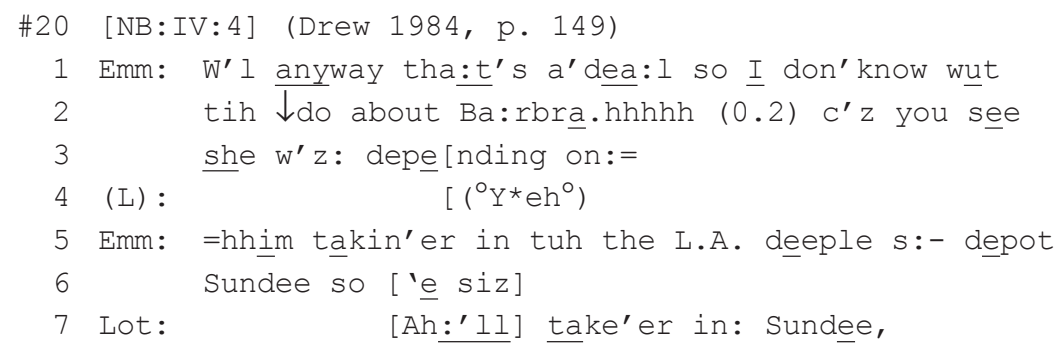

To claim that a report or display of a problem is an alternative to a request is not to say, however, that a speaker "intends" to ask a recipient for help but recruits his or her assistance through other means. The complementarity of reports of problems and requests for solutions is a public phenomenon, independent from the private experiences of the participants. The set of possible motives that a speaker may have to talk to others about his or her problems is surely large and varied, but, insofar as problems need solutions, reporting a problem is in principle an alternative to requesting a solution.

That said, speakers can and do use reports and displays of problems to elicit offers of assistance. The sequence in Extract 21 comes from an interaction between a group of friends as they prepare a barbecue in a public park. As one participant chops a head of cabbage, she appears to encounter trouble - her knife wobbles and her cuts appear 
exaggerated and uneven. At this moment, she calls the name of her boyfriend, who happens to be a professional sous-chef, using a hearably "whining" voice quality.

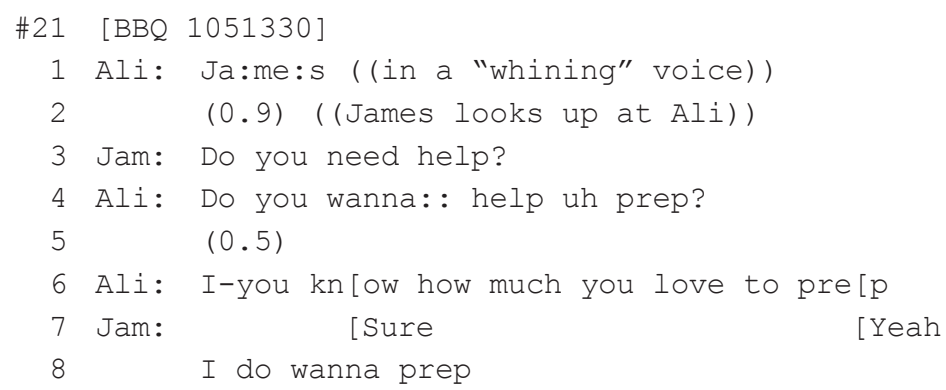

A summons or generic pre-sequence is one common practice through which speakers manage the attention and alignment of a recipient prior to the production of a base first pair-part of an adjacency-pair sequence (Schegloff 2007) (see the discussion above of Gordon's enquiry in Extract 2). Ali's summons thus projects the relevance of a base first pair part, one that she noticeably fails to produce after James redirects his gaze to her. The hearably "whining" voice quality of the summons simultaneously indexes a problem or trouble and projects that the base first pair part will pertain to the problem. After the first pair part does not arrive, James must work out what relevance the summons and the problem it indexes have to him. It is in this sequential environment that he produces an offer of help (just parenthetically, note that this is also an example of the first relationship we outlined, in which an offer [line 3] is responded to by a request [line 4]). Thus, in contrast to the previous case, in which Emma reports a problem to Lottie, Ali's problem-indexical summons appears to have been designed to elicit an offer of help.

The formulation of a possible or actual absence is another practice to display a problem, lack, or need for something. In Extract 22, Lisa picks up a bag of candy from the table, one that has been shared between the members of the group, tips the bag over, empties its contents into her hand, and sets the bag back on the table. Ben, who has just seen this, inquires about the candies.

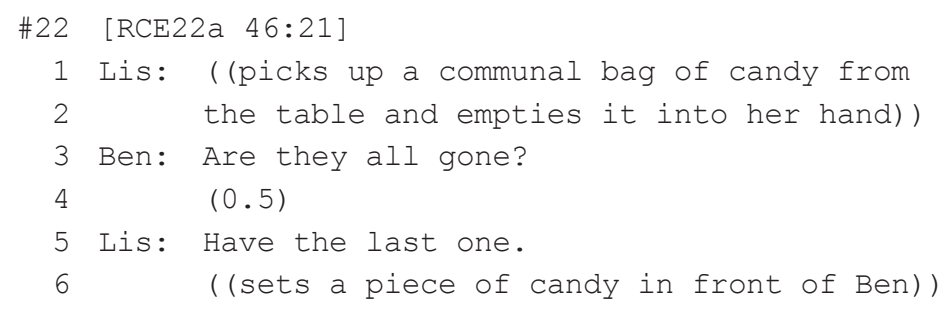

Lisa has reason to believe that Ben already knows the answer to his enquiry in line 3; he's just seen Lisa empty the bag. Hence she has grounds to analyse his enquiry as not 
really a request for information (Heritage 2012) but rather as a complaint, or perhaps a preliminary to a complaint. The reference to the candy as the last one in her offer orients to grounds for a complaint, namely that she has taken the last piece of candy. In this case, then, a question about a possible lack of an object serves as a preliminary to a complaint and thereby occasions an offer that undermines the complainability of the recipient's actions. The formulation of an absence or lack of an object, while not a request per se, can provide an occasion for an offer and therefore serve to effect an object transfer.

The relevance of a solution upon the production of a recognizable report or display of a problem does not depend, however, on whether the report or display could be understood by the recipient as having been made in the service of indicating that the speaker wants something, and therefore that this is some alternative to a request. In the next case, as two students sit on a bench on a university campus, one reports a minor problem, her hunger, which elicits an offer of something to eat. The details of the case suggest, however, that the report of hunger was not selected as an alternative to a request.

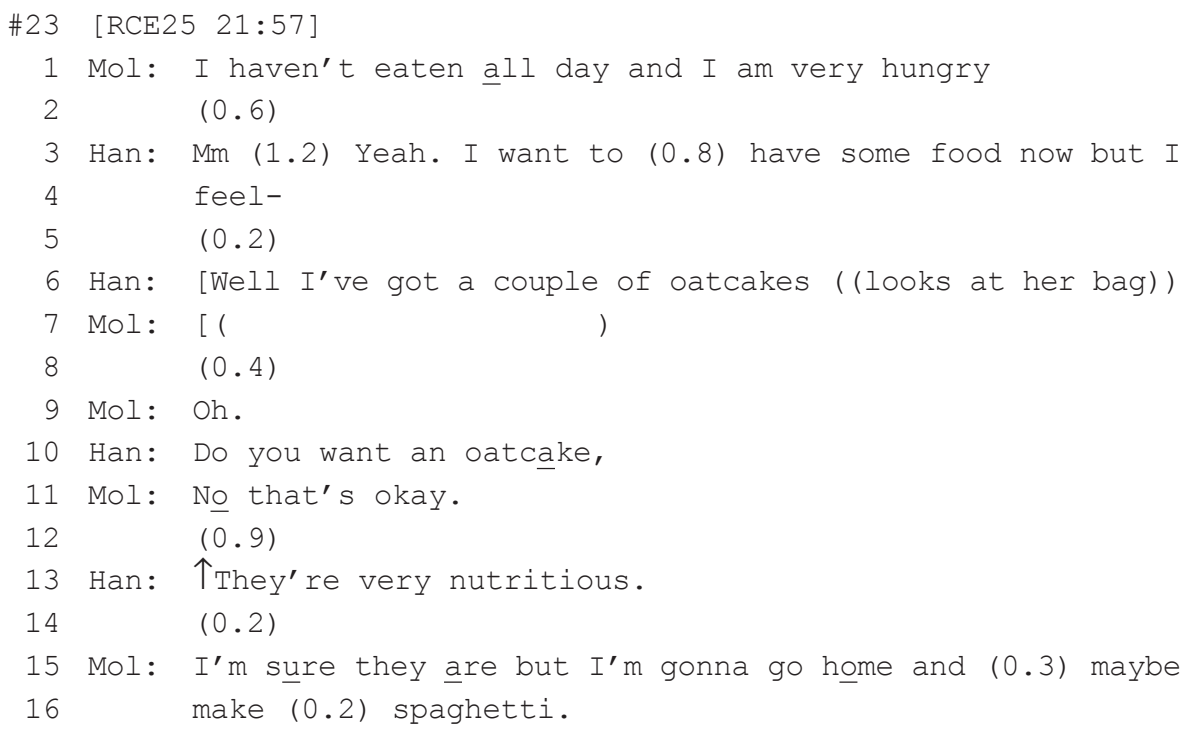

Although the report of the problem provides an occasion for the offer, in this case, an explicit request is not a locally-relevant or available alternative. Two arguments support this conclusion. The first is that the report is recognizable in context as a vehicle for other actions. Prior to this extract, talk had turned to the time and the whereabouts of the researcher, who has left the participants to talk but must return to collect the equipment before the session can conclude. Within this context, Molly's report of hunger is recognizable both as a complaint about the current situation and as a reason to 
leave the session sooner rather than later. Although Hanna's initial response orients to this, insofar as it also cites eating as an alternative to the current activity (lines 3-4), she abandons this TCU before it comes to completion and launches a new TCU, an offer of oatcakes (line 6), which serves as a possible solution to the problem of Molly's hunger, and perhaps her own as well. The second argument concerns the requestability of the object in question. Given that the object of the offer, which the direction of Hanna's gaze suggests is hidden away in her bag, is not visible to the speaker, the oatcakes are not themselves requestable - Molly does not know of their existence. The format of Hanna's offer, an informing of possession, also orients to the status of the object as unknown to Molly. Taken together, the evidence suggests that the report of a problem in this case was not produced as, nor could be recognized by its recipient as, an alternative to a request. The sequential relevance of an offer of a solution to a problem thus appears to depend neither on the recognizability of the report as an alternative to a request, nor on the requestability of the solution.

\subsection{Ungrantable requests can occasion offers of alternatives}

A fifth relationship between offers and requests involves the offering of alternative objects after unsuccessful requests. A speaker who requests an object for a particular task may find that the recipient is unable to grant the request. Under these circumstances, a third party may intervene with an offer of some alternative. The sequence in Extract 24 come from an interaction between a group of university students in a common area of a university building. After Megan noticed that the battery on Rachel's laptop, which Megan has been using, is nearly out of power, she asks Rachel for the laptop's power supply.

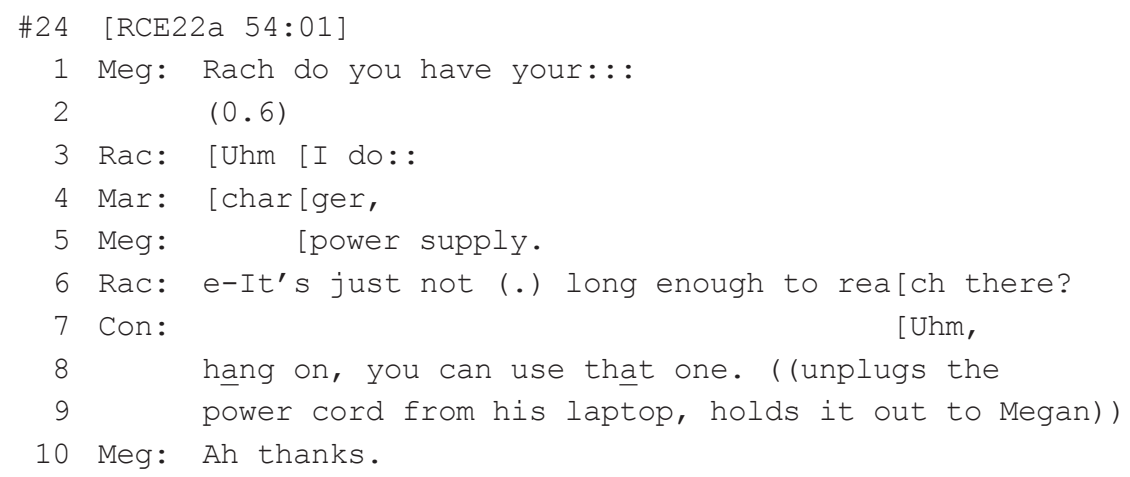

The response that Rachel produces details a specific circumstance that prevents her from granting Megan's (implied) request, namely that the power cord is not long enough to reach from the outlet to the laptop; this amounts to a denial of the request (Drew 1984). Upon the recognizable completion of Rachel's denial, Connor reaches 
for the power cord on his own laptop, which is the same make as Rachel's, unplugs it and hold it out to Megan, as he simultaneously produces a verbal offer. Although the denial may technically complete the sequence, insofar as it constitutes a second pair part in the request sequence, it nonetheless fails to resolve the speaker's problem, and the sequence remains incomplete until the solution is found.

A similar sequence emerges in the next case, which comes from the same barbecue preparations as Extract 21. Prior to this extract, Donna has gone off camera in order to smoke marijuana, discretely. After her request for a pipe cannot be granted, Carrie offers her an apple, which can be formed into an ad hoc pipe, as an alternative. Similarly, moments later, a request for a knife to carve the apple receives an offer of a pen as a workable substitute.

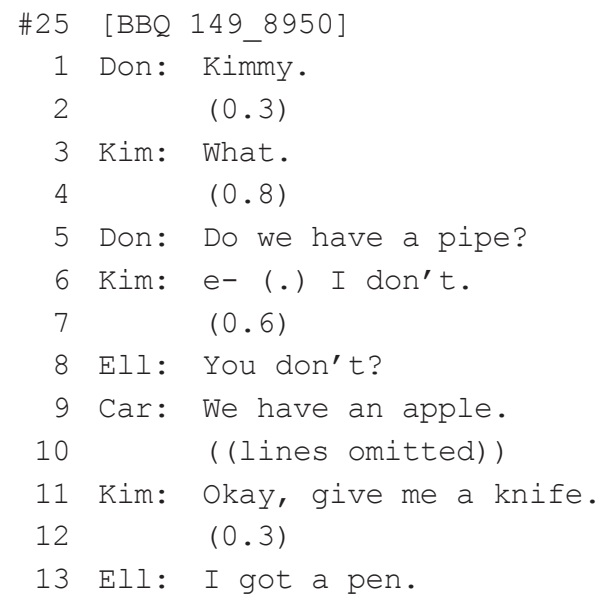

In these examples, a request that a recipient is unable to grant creates a sequential environment for an unaddressed recipient to intervene with an offer of an alternative, but workable, solution to the speaker's problem.

\section{Conclusion}

We have argued here that the evidence proposed in support of a preference for offers over requests does not withstand close scrutiny. Insofar as properties that might be associated with the dispreferred status of requests hold for offers as well, there is no reason to conclude that offers are generally the preferred alternatives to requests. In the place of a general preference for offers, we have identified and described an open set of relatively more concrete relationships between offering and requesting in conversation. While we do not wish to replace one abstract relationship with another, we do wish to highlight and further articulate a theme running through this set of 
relationships and through many, but not all, of the cases that we have examined. That theme is as follows: requests concern the need for assistance that speakers may have, needs arising from problems, absences, desires and the like. Their requests for assistance simultaneously index both their need (e.g. a problem) and a possible solution that may be provided or rendered by co-present others (recipients). Seen in this light, we are able to account for a range of phenomena associated with requesting, including (i) a relationship between requests and reports and displays of problems, (ii) a relationship between problems and offers of solutions, and ultimately (iii) the possibility of a circuitous relationship between some offers and requests.

In many of the cases that we have considered, what is at stake for the one making a request is a course of action that, without some form of assistance, cannot progress beyond its current state. For example, in Extract 1, Gordon evidently needs a letter from the county council in order to pay his tuition; in Extract 3, Ann apparently plans to smoke a cigarette but lacks a necessary instrument, a match; in Extract 24, a low battery threatens to disrupt Megan's use of a computer unless she can find a power cord. In such cases, the requester lacks a relevant object or is unable to perform a relevant service that is necessary for a course of action - one already set in motion by the requester - to progress beyond its current state, to completion. In other cases, a request does not index a problem with the realization of a course of action, but rather a relatively transient, and at times locally occasioned, "want" or "desire", the fulfillment of which is contingent on the actions of others (e.g. the request to play a game in Extract 16 and the requests for biscuits in Extract 17).

Requests not only index problems, in this abstract sense of the term, but also present recipients with possible solutions, which recipients are asked to provide. While speakers' problems may merely be indexed tacitly (unless an account is given), possible solutions are articulated explicitly in the request itself. The request in Extract 1 (could you bring up a letter when you come up) explicitly formulates an action that the recipient can perform to resolve the speaker's problem; and the requests in Extract 3 (can I have a match) and Extract 24 (do you have your power supply) name objects that could enable the courses of action to which the requests belong to move forward. This account of requests, in which they are described in terms of contingencies and problems that arise in particular circumstances, and their possible "solutions" (assistance), begins to shift the analytic focus away from the actions of the recipient - who under a more traditional account is "directed" (Searle 1976) or "controlled" (Ervin-Tripp 1976, 1982) by the one making the request - and instead towards the circumstances in which someone may make a request, or by indicating that they may need the other's assistance may recruit the other to assist; or indeed towards circumstances in which the other may anticipate someone's need for assistance.

While the act of requesting both indexes a speaker's problem and presents a recipient with a possible solution, these two elements need not occur together in the same 
action. Indeed, as the cases presented in the previous sections demonstrate, an indication of a problem and an offer of a solution can be distributed sequentially across two actions, by two different participants. The result is a sequence that can achieve the same outcome as a request sequence (i.e. the resolution of a speaker's problem), but has a very different organization. A request creates a normative obligation for the recipient to produce a response that accepts or rejects the request, frequently but not exclusively through interrogative or imperative grammatical formats which set normative constraints on the appropriate forms of response (see also Couper-Kuhlen 2014). A request is, in other words, a first pair-part of an adjacency-pair sequence, making a restricted set of next actions conditionally relevant (Schegloff \& Sacks 1973; Schegloff 2007).

In contrast, the sequences that can emerge through reports or displays of problems and offers of possible solutions in next position do not employ the machinery of the adjacency pair, and thus embody a very different set of social relations between speaker and recipient. Rather than establish a normative obligation for the recipient to commit to the provision of assistance, a report or display of a problem creates an opportunity for a recipient to offer assistance, as a sequence-initiating or first position action. Heritage and Raymond (2005) have argued that first position carries a tacit claim of independence and primacy, to which we add that first position is also a locus for the expression of agency in interaction (cf. Heritage \& Raymond 2012). While a recipient who grants a request submits to the agency of the requester, agreeing to implement a solution devised by the requester, the recipient of a report or display of a problem finds him- or herself in a position to offer assistance voluntarily, and to determine his or her own solution to the problem, thereby exercising a greater degree of agency over the course of action.

The observation that indications of problems commonly elicit offers of assistance suggests that there may be a normative, though not necessarily obligatory, relationship between recognizable problems and offers of solutions in social interaction. To what extent this is so remains an open question, one which we leave for future research. But the significance of the question is clear. The propensity to help or assist others has been proposed as a basic social motive and cited as a foundation for human cooperation (Tomasello 2008). The documentation of this social motive, as enacted through sequences of action, promises to ground theoretical claims such as these in the observable conduct of participants in spontaneous interaction.

Taken together, these observations point to the possibility of a symbiotic relationship between offering and requesting in conversation. A speaker who encounters a problem in the realization of a course of action has available at least two alternative actions through which assistance may be sought: a report of a problem, which may (or may not) elicit an offer, or a request that presents a recipient with a possible solution to accept or reject. In such cases, offering and requesting do not have a direct relationship; 
but through the selection of problem reports or displays as alternatives to requests, an indirect relationship between these actions emerges. Does this relationship constitute evidence for a preference for offers? One could argue that this circuitous path "demotes" requests, insofar as speakers do not produce them, and "promotes" offers; but the availability of a path that bypasses requesting yet achieves the same outcome is not itself sufficient evidence for a preference for offers. In sum, we have seen how in particular interactional circumstances, someone lets it be known, somehow, that they might need assistance; and someone else comes to anticipate that need before the other has let it be known, or to discern that need, whether or not the other explicitly or implicitly recruited them to assist.

\section{Acknowledgements}

A subset of the data used in this study came from the Language and Social Interaction Archive (2014). We would like to thank Leah Wingard for this excellent resource.

\section{References}

Brown, Penelope, and Stephen C. Levinson. 1987. Politeness: Some Universals in Language Usage. Cambridge: Cambridge University Press.

Clayman, Steven E. 2002. "Sequence and Solidarity." In Group Cohesion, Trust and Solidarity, Vol. 19, ed. by Shane R. Thye, and Edward J. Lawler, 229-253. Oxford: Elsevier Science Ltd.

Couper-Kuhlen, Elizabeth. 2014. "What Does Grammar Tell Us About Action?” Pragmatics 24 (3): 623-647.

Curl, Traci S. 2006. “Offers of Assistance: Constraints on Syntactic Design." Journal of Pragmatics 38 (8): 1257-1280. DOI: 10.1016/j.pragma.2005.09.004

Drew, Paul. 1984. “Speakers' Reportings in Invitation Sequences." In Structures of Social Action: Studies in Conversation Analysis, ed. by J. Maxwell Atkinson, and John Heritage, 129-151. New York: Cambridge University Press.

Ervin-Tripp, Susan. 1976. "Is Sybil There? The Structure of Some American English Directives." Language in Society 5 (1): 22-66. DOI: 10.1017/S0047404500006849

Ervin-Tripp, Susan. 1982. "Structures of Control." In Communicating in the Classroom, ed. by L. C. Wilkinson, 27-47. New York: Academic Press.

Goffman, Erving. 1955. “On Face-Work: An Analysis of Ritual Elements in Social Interaction." Psychiatry: Journal for the Study of Interpersonal Processes 18: 213-231.

Heritage, John. 1984. Garfinkel and Ethnomethodology. Cambridge: Polity Press.

Heritage, John. 2012. "Epistemics in Action: Action Formation and Territories of Knowledge." Researchon Language \& SocialInteraction 45(1): 1-29.DOI: 10.1080/08351813.2012.646684

Heritage, John, and Geoffrey Raymond. 2005. “The Terms of Agreement: Indexing Epistemic Authority and Subordination in Talk-in-Interaction." Social Psychology Quarterly 68: 15-38. DOI: $10.1177 / 019027250506800103$ 
Heritage, John, and Geoffrey Raymond. 2012. "Navigating Epistemic Landscapes: Acquiescence, Agency and Resistance in 'Repetitive' Responses to Polar Questions." Questions, ed. by Jan Peter de Ruiter. 179-192. Cambridge: Cambridge University Press.

Language and Social Interaction Archive. 2014. Available from San Francisco State University. http://www.sfsu.edu/ lsi/

Lerner, Gene H. 1996. "Finding 'Face' in the Preference Structures of Talk-in-Interaction." Social Psychology Quarterly 59 (4): 303-321. DOI: 10.2307/2787073

Levinson, Stephen C. 1983. Pragmatics. Cambridge: Cambridge University Press.

Lindström, Anna. 2005. "Language as Social Action: A Study of How Senior Citizens Request Assistance with Practical Tasks in the Swedish Home Help Service." In Syntax and Lexis in Conversation: Studies on the Use of Linguistic Resources in Talk-in-Interaction, ed. Auli Hakulinen, and Margret Selting, 209-230. Amsterdam: John Benjamins

Robinson, Jeffrey D., and Galina B. Bolden. 2010. "Preference Organization of Sequence-Initiating Actions: The Case of Explicit Account Solicitations." Discourse Studies 12 (4): 501-533. DOI: $10.1177 / 1461445610371051$

Sacks, Harvey. 1992a. Lectures on Conversation, Vol. 1.2 vols. ed. by Gail Jefferson. Cambridge, MA: Blackwell Publishers.

Sacks, Harvey. 1992b. Lectures on Conversation, Vol. 2.2 vols. ed. by Gail Jefferson. Cambridge, MA: Blackwell Publishers.

Schegloff, Emanuel A. 1979. "Identification and Recognition in Telephone Conversation Openings." In Everyday Language: Studies in Ethnomethodology, ed. by George Psathas, 23-78. New York: Irvington.

Schegloff, Emanuel A. 1984. "On Some Questions and Ambiguities in Conversation." In Structures of Social Action, ed. J. Maxwell Atkinson, and John Heritage, 266-298. Cambridge: Cambridge University Press.

Schegloff, Emanuel A. 2007. Sequence Organization in Interaction: A Primer in Conversation Analysis. Cambridge: Cambridge University Press. DOI: 10.1017/CBO9780511791208

Schegloff, Emanuel A., and Harvey Sacks. 1973. “Opening Up Closings." Semiotica 8 (4): 289-327. DOI: 10.1515/semi.1973.8.4.289

Searle, John R. 1976. "A Classification of Illocutionary Acts." Language in Society 5 (1): 1-23. DOI: $10.1017 /$ S0047404500006837

Tomasello, Michael. 2008. Origins of Human Communication. Boston: MIT Press. 